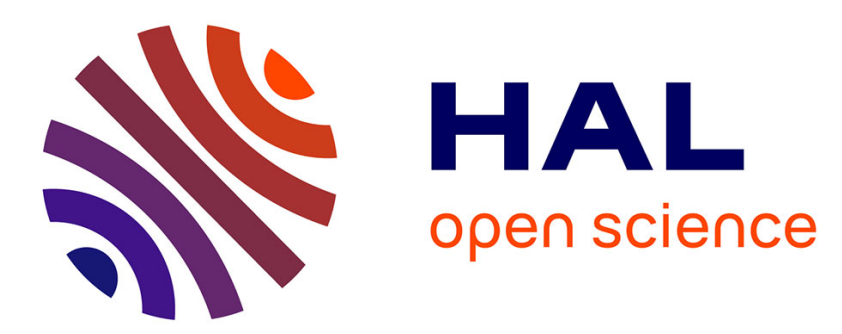

\title{
Large intra-individual variability of plasma cytokines in healthy young men : a two 24-h study over a month
}

\author{
Brahim Selmaoui, Linda Sackett-Lundeen, Erhard Haus, Yvan Touitou
}

\section{To cite this version:}

Brahim Selmaoui, Linda Sackett-Lundeen, Erhard Haus, Yvan Touitou. Large intra-individual variability of plasma cytokines in healthy young men : a two 24-h study over a month. Biological Rhythm Research, 2016, 47 (2), pp.267-273. 10.1080/09291016.2015.1108060 . ineris-01855198

\section{HAL Id: ineris-01855198 \\ https://hal-ineris.archives-ouvertes.fr/ineris-01855198}

Submitted on 27 Sep 2018

HAL is a multi-disciplinary open access archive for the deposit and dissemination of scientific research documents, whether they are published or not. The documents may come from teaching and research institutions in France or abroad, or from public or private research centers.
L'archive ouverte pluridisciplinaire HAL, est destinée au dépôt et à la diffusion de documents scientifiques de niveau recherche, publiés ou non, émanant des établissements d'enseignement et de recherche français ou étrangers, des laboratoires publics ou privés. 


\section{Large intra-individual variability of plasma cytokine in healthy young men: a two 24h study over a month}

\section{${ }^{1,2}$ Brahim Selmaoui, ${ }^{3}$ Linda Sackett-Lundeen, ${ }^{3}$ Erhard Haus \& ${ }^{4}$ Yvan Touitou}

${ }^{1}$ Department of Experimental Toxicology, INERIS, Parc ALATA, BP2, 60550 Verneuil-en-Halatte, France

${ }^{2}$ Université de Picardie Jules Verne, Peritox Laboratoire de Périnatalité \& Risques Toxiques UMRI-01Unité mixte INERIS, 80480 Salouel, France

${ }^{3}$ HealthPartners Medical Group, Regions Hospital, University of Minnesota Medical School, St. Paul, MN 55101, USA

${ }^{4}$ Unité de Chronobiologie, Fondation Ophtalmologique A. de Rothschild, 75019 Paris, France

Short title: intra-individual variability of plasma cytokine

Keywords: Cytokines, variability. IL-6, IL-1 beta, IL-2, IL-1RA, IL-2R

Corresponding author:

B. Selmaoui (PhD, HDR)

Department of Experimental Toxicology, INERIS,

Parc ALATA, BP2,

60550 Verneuil-en-Halatte, France

E-mail: brahim.selmaoui@ineris.fr 


\section{Abstract}

Cytokines levels in blood are not yet fully considered as a biomarker for disease even if some significant progresses have been made in linking certain cytokines to some diseases. The aim of this present study was to look for the stability of some cytokines in blood collected in two different days separated by one month. Fifteen healthy young men aged 20 to 30 years were selected for this study. Each subject participated in two 24-hour sessions spaced a month apart. Blood sample was taken at 11:00, 17:00, 22:00, 01:00, 04:00, 06:00, and 08:00. Concentrations of interleukin-6, interleukin-1-receptor antagonist, soluble IL-2 receptor, interleukin-1beta, and interleukin-2 were measured in serum. The circadian pattern of each variable was compared between the two days. The results show that there is no reliability for the measured cytokines. This study shows that cytokine levels measured in blood is far being the reliable variables or to be considered as stable markers in healthy subjects.

\section{Introduction}

Cytokines mediate and regulate immunity, inflammation, and hematopoiesis (Thomson and Lotze, 2003). They are produced de novo in response to an immune stimulus when facing a major physiological challenge. The complexity of these small proteins resides in their pleiotropic character which means that different cell types secrete the same cytokine or that a single cytokine acts on several different cell types. Additionally, cytokines are also redundant in their activity, i.e., several cytokines may share the same activity. All these properties render the comprehension of the physiological and pathophysiological role of cytokines less well understood. Another aspect of difficulties is that cytokines are produced within tissues and this makes their evaluation somewhat difficult in human. Thus measurements of cytokines in blood are more common. But the question aroused is whether cytokine levels measured in blood are reliable from day to day in the same subject. It should be noted that cytokines levels in blood are not yet fully considered as a biomarker for disease even if some significant progresses have been made in linking certain cytokines to some 
diseases. This is why the study of the stability of cytokine production may help in providing information concerning cytokines and their clinical usefulness in measuring cytokines levels in serum.

\section{Subjects and protocol}

This work is part of the broad study on the effect of ELF electromagnetic field on the immune system (Selmaoui et al. 2011). Data from control group who were not exposed were processed for this study. Healthy young men (12-15), aged 20 to 30 years, were selected after routine clinical and laboratory examination. Selection criteria included regular sleep habits, no chronic disease or disability, no recent acute illness; none were taking drugs or medications, no night work, no travel to another time zone within the preceding 2 months, and no smoking.

Each subject participated in two 24-hour sessions (D1 and D2) spaced a month apart. Catheters were placed in the antecubital vein for the 24-hour period, and the first blood sample was taken at 11:00, 17:00, 22:00, 01:00, 04:00, 06:00 and 08:00. The local ethics committee of the Pitié Salpêtrière approved this protocol.

\section{Cytokine assay}

IL-1RA (R\&D System, Minneapolis, MN, USA), IL-2R (Genzyme Corporation, Cambridge, MA, USA), IL-1 $\beta$, IL-2, and IL-6 (Biosource, Europe S.A., Fleurus Belgium), were assayed by ELISA in duplicate using serum samples drawn during the two 24-h study days. Sampling occurred at 11:00, 17:00, 22:00, 01:00, 04:00, 06:00, and 08:00. Inter- and intra-assay coefficients of variation vary between 4 and $20.5 \%$ (see Selmaoui et al 2011).

\section{Statistical analysis}


The reliability of the measures of serum cytokines was analyzed by the test retest reliability intraclass correlation coefficient (ICC). The ICC is usually relevant in assessing inter-rater reliability or to evaluate the stability of a measure over time (Shrout and Fleiss, 1979). For each subject, the ICC was calculated to determine the reliability between the 2 days for the 7 recording points on a daily basis. Significance was tested when the $95 \%$ confidence interval of the coefficient did not contain 0 .

In addition, the data were analyzed as a group for circadian rhythm by a computerized inferential statistical method (mean population cosinor) involving the fit of a 24-hour cosine curve by the method of least squares, rhythm detection considered statistically significant when $P$ is 0.05 or less.

\section{Results and Discussion}

The ICC has shown no reliability for the measured cytokines (IL-6, IL1 $\beta$, IL2, IL-1RA, sol IL-2R)

(Table 1). This shows a large variability in secretion in the young and healthy subjects between day 1 and day 2 spaced a month apart.

With regard to the circadian variations, the serum mean concentrations of IL6 showed a significant day night variation during the first session of sampling (Table 2). However this variation was not significantly observed in the second session of sampling (day 2). No other cytokines measured (IL1 $\beta$; IL-1RA; IL-2, and sol IL-2R) changed significantly (Table2). The serum mean concentrations of IL6 began to rise in the afternoon, and reached a peak during the evening hours.

Thus, this study shows that cytokine levels measured in blood is far being the reliable variables or to be considered as stable markers in healthy subjects, unlike cortisol and melatonin (Selmaoui and Touitou, 2003). This variation in the secretion may be a result of the higher sensitivity of these proteins since they are produced when body is facing infections, injuries, or tissue trauma. The fact that cytokines are involved in the immune system, their alterations in the production, and their levels in serum, plasma and body fluids reflect the changes in the equilibrium of the immune system. Thus, measuring cytokine levels in blood is somewhat indicative of the severity degree of 
infection in human being, but in our study, subjects are healthy and the intra-individual variations can be ascribed to a response to environmental aggressor such as stress which is thought to affect immune system and increases susceptibility to infection (Dhabhar, 2003; Rohleder et al. 2012). It is possible that stress could be one among other factors that may lead to the significant variation in cytokine production. Additionally, some studies have investigated the effect of partial or total sleep deprivation on cytokine levels in healthy subjects and found increased levels of IL-6 (Irwin et al., 2006; Vgontzas et al., 2004; Shearer et al., 2001; Gundersen et al., 2006; Voderholzer et al., 2012), and IL-1RA (Frey et al., 2007).

The other factors that could induce a variation in the cytokine production seem to be related to diet. Actually, previous studies have shown an association between the intake of $n-3$ fatty acids and lower concentrations of inflammatory markers (Brown et al., 2001). Other studies have also shown changes in CRP and IL-6, when subjects were supplemented with $\alpha$-linolenic acid or oils rich in long-chain n-3 fatty acids (Ciubotaru et al., 2003; Thies et al., 2001). On the other hand, diets high in trans fat or saturated fat were found to be associated with higher concentrations of CRP and IL-6, in a randomized crossover study in men (Baer et al., 2004). In another study, consumption of fish oil and vitamin E inhibited the production of IL-1 $\beta$ and IL-6 (Wu et al., 2004) while high fat diet affects the 24-hour pattern of circulating adipocytokines in rats (Cano et al., 2009). Taking into account of the above results, it is plausible that significant variations of cytokine production observed in healthy men could be related to specific dietary intake which was not controlled in our study.

In conclusion, our study shows that a great variation in cytokine production exists in the same subject from day-to-day sampling. Thus, this study is in accordance with the previous one (Cava et al., 2000) in which serum IL-6 and sIL-2R have shown a much higher variability within subjects. The cause of these intra-individual variations remains unclear and raises question about the relevance of cytokines assays in peripheral blood and their significance in clinical study. However, it remains worthwhile to examine theses biomarkers in relation to diseases and other inflammation- 
related chronic diseases even with a single measurement since the large variation in theses cytokines between patients and their respective control group may exceed the intra-individual variation.

Finally, this intra-individual variability added to the weakness in the cytokine assays which is not performed as routine clinical laboratory procedures (Cava et al., 2000; Whiteside, 2002) makes cytokine monitoring much complex.

\section{Acknowledgments:}

This study was supported by a grant from le "Ministère de l'Environnement Français" (French Ministry of the Environment). This work was my last collaboration (BS) with doctor E.Haus before he passed away and this publication is dedicated to his memory and for all he had brought to chronobiology.

\section{References:}

Baer DJ, Judd JT, Clevidence BA, Tracy RP. 2004. Dietary fatty acids affect plasma markers of inflammation in healthy men fed controlled diets: a randomized crossover study. Am J Clin Nutr. 79:969-973.

Brown AA, Hu FB. 2001. Dietary modulation of endothelial function: implications for cardiovascular disease. Am J Clin Nutr. 73:673-86.

Cano P, Cardinali DP, Ríos-Lugo MJ, Fernández-Mateos MP, Reyes Toso CF, Esquifino AI. 2009. Effect of a high-fat diet on 24-hour pattern of circulating adipocytokines in rats. Obesity. 17(10):1866-1871.

Cava F, Gonzalez C, Pascual MJ, Navajo JA, Gonzalez-Buitrago JM., 2000. Biological variation of interleukin 6 (IL-6) and soluble interleukin 2 receptor (sIL2R) in serum of healthy individuals. Cytokine. 12(9):1423-5.

Ciubotaru I, Lee YS, Wander RC. 2003. Dietary fish oil decreases C-reactive protein, interleukin-6, and triacylglycerol to HDL-cholesterol ratio in postmenopausal women on HRT. J Nutr Biochem. 14:513-21. 
Dhabhar FS. 2003. Stress, leukocyte trafficking, and the augmentation of skin immune function. Ann N Y Acad Sci. 992:205-217.

Frey DJ; Fleshner M; Wright KP Jr. 2007. The effects of 40 hours of total sleep deprivation on inflammatory markers in healthy young adults. Brain Behav Immun. 21:1050-1057.

Gundersen Y, Opstad PK, Reistad T, Thrane I, Vaagenes P. 2006. Seven days' around the clock exhaustive physical exertion combined with energy depletion and sleep deprivation primes circulating leukocytes. Eur J Appl Physiol. 97:151-157.

Irwin MR; Wang M; Campomayor CO, Collado-Hidalgo A, Cole S. 2006. Sleep deprivation and activation of morning levels of cellular and genomic markers of inflammation. Arch Intern Med. 166:1756-1762.

Selmaoui B, Lambrozo J, Sackett-Lundeen L, Haus E, and Touitou Y. 2011. Acute exposure to 50-Hz magnetic fields increases Interleukin-6 in young healthy men. Journal of Clinical Immunology. 31:1105-1111.

Selmaoui B and Touitou Y. 2003. Reproducibility of the circadian rhythms of serum cortisol and melatonin in healthy subjects. A study of three 24-h cycle over six weeks. Life Sciences. 73 (26): 3339-3349.

Shearer WT; Reuben JM; Mullington JM, Price NJ, Lee BN, Smith EO, Szuba MP, Van Dongen HP , and Dinges DF. 2001. Soluble TNF-alpha receptor 1 and IL-6 plasma levels in humans subjected to the sleep deprivation model of spaceflight. J Allergy Clin Immunol. 107:165-170.

Shrout PE, Fleiss, JL. 1979. Intraclass correlations: uses in assessing rater reliability. Psychological Bulletin. 86(20):420-428.

Thies F, Miles EA, Nebe-von-Caron G, Powell JR, Hurst TL, Newsholme EA, Calder PC. 2001. Influence of dietary supplementation with long-chain $n-3$ or $n-6$ polyunsaturated fatty acids on blood inflammatory cell populations and function and on plasma soluble adhesion molecules in healthy adults. Lipids. 36:1183-1193.

Thomson AW, and Lotze MT. (Eds.). 2003. The Cytokine Handbook. London: Academic Press. 
Vgontzas AN, Zoumakis E, Lin HM, Bixler EO, Trakada G, Chrousos GP. 2004. Marked decrease in sleepiness in patients with sleep apnea by etanercept, a tumor necrosis factor-alpha antagonist. J Clin Endocrinol Metab. 89:4409-4413.

Voderholzer U, Fiebich BL, Dersch R, Feige B, Piosczyk H, Kopasz M, Riemann D, Lieb K. 2012. Effects of sleep deprivation on nocturnal cytokine concentrations in depressed patients and healthy control subjects. J Neuropsychiatry Clin Neurosci. 24(3):354-66.

Whiteside TL. Cytokine assays. 2002. Biotechniques. Suppl:4-8, 10:12-15.

Wu D, Han SN, Meydani M, Meydani SN. 2004. Effect of concomitant consumption of fish oil and vitamin $\mathrm{E}$ on production of inflammatory cytokines in healthy elderly humans. Ann N Y Acad Sci. 1031:422-424. 


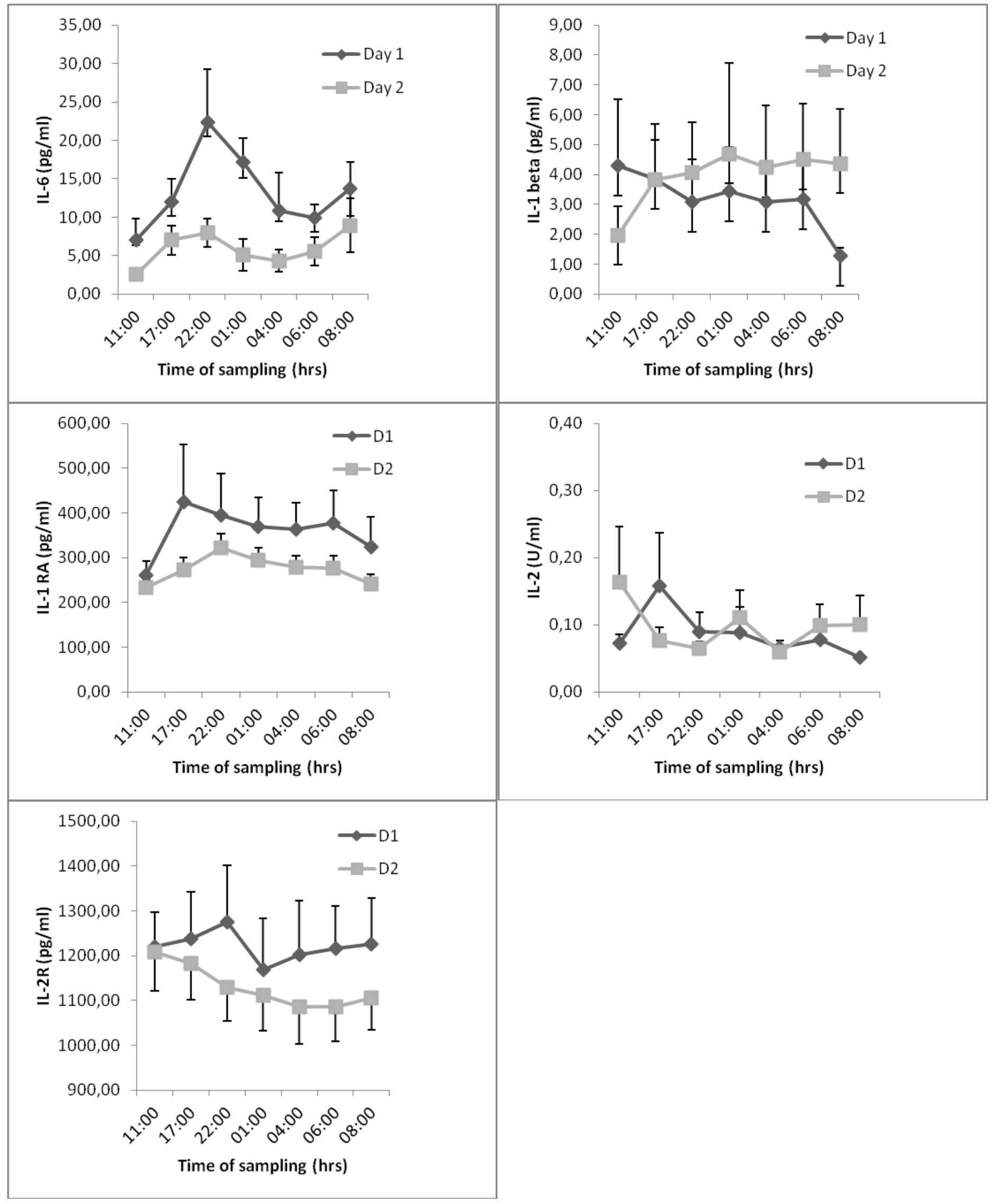

Figure 1: The pattern of serum cytokine (IL-6, IL-1ß, IL-1RA, IL-2 and IL-2R) variation in healthy volunteers sampled in two different days (D1 and D2) spaced a month apart. 
Table 1: The ICC compared the similarity of the 7 time-of-day measures between the 2 days for each variable.

\begin{tabular}{|c|c|c|c|c|c|c|c|c|c|c|c|c|c|c|c|}
\hline \multirow[b]{2}{*}{ Subjects } & \multirow{2}{*}{\begin{tabular}{|l|} 
ICC \\
IL-6 \\
\end{tabular}} & \multicolumn{2}{|c|}{$95 \% \mathrm{CI}$} & \multirow{2}{*}{$\begin{array}{l}\text { ICC } \\
\text { IL-1 beta } \\
\end{array}$} & \multicolumn{2}{|c|}{$95 \% \mathrm{CI}$} & \multirow{2}{*}{\begin{tabular}{|l|} 
ICC \\
IL-1 RA \\
\end{tabular}} & \multicolumn{2}{|c|}{$95 \% \mathrm{CI}$} & \multirow{2}{*}{$\begin{array}{l}\text { ICC } \\
\text { IL-2 }\end{array}$} & \multicolumn{2}{|c|}{$95 \% \mathrm{CI}$} & \multirow{2}{*}{\begin{tabular}{|l|} 
ICC \\
Sol IL-2 R \\
\end{tabular}} & \multicolumn{2}{|c|}{$95 \% \mathrm{CI}$} \\
\hline & & Lower & Upper & & Lower & Upper & & Lower & Upper & & Lower & Upper & & Lower & Upper \\
\hline S1 & 0,2 & $-0,53$ & 0,80 & 0,0 & $-0,60$ & 0,67 & 0,0 & $-0,53$ & 0,67 & - & - & - & 0,3 & $-0,14$ & 0,78 \\
\hline S2 & $-0,2$ & $-0,90$ & 0,60 & 0,7 & $-0,04$ & 0,96 & $-0,1$ & $-0,28$ & 0,46 & 0,6 & $-0,17$ & 0,91 & 0,1 & $-0,88$ & 0,77 \\
\hline S3 & 0,5 & $-0,17$ & 0,89 & 0,0 & $-0,53$ & 0,67 & $-0,1$ & $-0,65$ & 0,64 & $-0,3$ & $-1,00$ & 0,58 & 0,4 & $-0,18$ & 0,84 \\
\hline S4 & $-0,1$ & $-0,51$ & 0,60 & $-0,1$ & $-0,69$ & 0,67 & $-1,1$ & $-0,34$ & 0,46 & 0,0 & $-0,75$ & 0,75 & $-0,2$ & $-0,45$ & 0,48 \\
\hline S5 & $-0,2$ & $-0,86$ & 0,72 & $-0,3$ & $-1,59$ & 0,93 & 0,0 & $-0,05$ & 0,27 & 0,8 & 0,08 & 0,98 & $-0,1$ & $-0,47$ & 0,72 \\
\hline S6 & 0,5 & $-0,41$ & 0,90 & - & - & - & 0,7 & $-0,07$ & 0,94 & 0,0 & $-0,69$ & 0,70 & 0,4 & $-0,14$ & 0,84 \\
\hline S7 & 0,3 & $-0,74$ & 0,83 & 0,0 & $-0,71$ & 0,71 & 0,0 & $-0,22$ & 0,49 & 0,0 & $-0,75$ & 0,75 & 0,1 & $-0,22$ & 0,62 \\
\hline S8 & $-0,1$ & $-0,70$ & 0,67 & $-0,1$ & $-0,74$ & 0,80 & 0,1 & $-0,09$ & 0,52 & 0,0 & $-0,71$ & 0,71 & 0,4 & $-0,62$ & 0,86 \\
\hline S9 & 0,3 & $-0,30$ & 0,83 & $-0,6$ & $-1,16$ & 0,33 & $-0,1$ & $-0,96$ & 0,71 & $-0,3$ & $-1,01$ & 0,59 & $-0,2$ & $-0,59$ & 0,55 \\
\hline S10 & 0,0 & $-0,54$ & 0,68 & $-0,2$ & $-0,51$ & 0,45 & 0,0 & $-0,13$ & 0,49 & 0,0 & $-0,56$ & 0,68 & $-0,1$ & $-0,12$ & 0,28 \\
\hline S11 & $-0,1$ & $-0,65$ & 0,63 & 0,7 & 0,04 & 0,94 & 0,3 & $-0,16$ & 0,81 & $-0,1$ & $-0,69$ & 0,63 & 0,1 & $-0,87$ & 0,77 \\
\hline $\mathrm{S} 12$ & 0,0 & $-0,13$ & 0,46 & 0,2 & $-0,76$ & 0,80 & 0,1 & $-0,51$ & 0,74 & $-0,1$ & $-0,62$ & 0,60 & 0 & $-0,11$ & 0,27 \\
\hline S13 & $-0,1$ & $-0,25$ & 0,45 & - & - & - & 0,4 & $-0,569$ & 0,87 & - & - & - & $-0,1$ & $-0,563$ & 0,62 \\
\hline S14 & $-0,2$ & $-0,86$ & 0,61 & 0,0 & $-0,71$ & 0,71 & 0,3 & $-0,62$ & 0,84 & 0,0 & $-0,75$ & 0,75 & 0,3 & $-0,51$ & 0,81 \\
\hline S15 & 0,2 & $-0,70$ & 0,83 & 0,0 & $-0,55$ & 0,67 & $-0,2$ & $-0,81$ & 0,60 & 0,0 & $-7,22$ & 0,71 & $-0,1$ & $-0,24$ & 0,43 \\
\hline
\end{tabular}

Table 2: The cosinor method was used to characterize the circadian rhythm of the variables. Rhythm detection considered statistically significant when $P$ is 0.05 or less.

\begin{tabular}{|l|l|l|}
\hline Cosine & D1 & D2 \\
IL-6 & $<.05$ & $>.05$ \\
IL-1 beta & $>.05$ & $>.05$ \\
IL-1 RA & $>.05$ & $>.05$ \\
IL-2 & $>.05$ & $>.05$ \\
Sol IL-2 R & $>.05$ & $>.05$ \\
\hline
\end{tabular}

